\title{
The Present Situation about the Education Management Direction of Master of Education Degree in Our Country
}

\author{
Da Yang \\ Jilin Agricultural University, Jilin, China \\ yangnan1983116@163.com
}

Keywords: Education management; Master of education degree; Graduate education

\begin{abstract}
Since 1996, China formally approved pilot professional master degree of education, the direction of education management in professional master degree postgraduate education has developed rapidly. But there are some problems in the development process, the paper proposes the corresponding improvement suggestions from training target, the recruitment of students test, curriculum setting, essay writing, generalizes the teachers configuration of these problems.
\end{abstract}

\section{Introduction}

Since 1996, China formally approved professional master degree of education, education management direction of professional master degree education developing rapidly what has been the basis of education and trained a large number of high-level management personnel. In the process of development, education management direction of education master degree education has experience and lesson. This paper briefly discussed the present situation and the tendency of the development of education from training target, the recruitment of students test, the curriculum, the respect such as essay writing.

\section{The Training Goal}

The degree system in China is divided into two types that are academic degrees and professional degrees. Academic degree is given priority to talent of education academic researchers, including scientific research ability of teachers. The setting of Professional degree is not based on science, it based on professional, it also called professional degree. Professional master degree of education is setting for primary and secondary school teachers in the field of education, school management, education administrative personnel set up professional degrees. Two types of degree difference determines the different training goal.

Many education institutions understanding the particularity of education master degree graduate student not enough, the existing training academic master experience, the training education master look very easy, not enough of types and specifications of its particularity, also can't see the exists gap objectively. The goal of cultivating the main problems of current is confusion, the occupational education master degree graduate students with the academic master graduate student of the same culture. Even training units repeatedly stressed the particularity of education master degree graduate student training objectives, the specific guidance level, a teacher also remain target confusion phenomenon. Not every tutor all clear training objectives, training process and training goal and coordinated.

After years of development, professional degree graduate education in our country has formed a relatively perfect management system, operation mechanism and policy system. They mainly reflect in: one is to form the central batchlor (ministry of education and the state council), local and degree-conferring unit as the main body of the management system. At the same time, professional degree graduate education organize and guide steering committee under the state council batchlor for professional degree postgraduate education play the role of research, guidance and coordination organization. The second is to set up government audit policy measures, college application and expert evaluation, the mechanism and competition mechanism guide the construction mechanism. Batchlor entrust a specialized degree in teaching refers to the committee under the state council to 
accept the application and organize expert evaluation. The lodge an application to the relevant professional degree taught in colleges and universities refers to the commission by teaching demonstration, research, evaluation and certification. The third is to build discipline expert guidance system, the professional degree has taught refers to the committee, its members form embodies the academic, representative and authoritative. The people should see that full-time professional degree graduate education in our country is still at the starting stage, in terms of systems and mechanisms and policies and regulations still are not perfected, such as the external mechanism is not sound, internal quality management and staffed yet to be strengthened, quality evaluation system needs to be established.

\section{The Recruitment of Students Test}

In recent years, the recruitment of students test exist the following problems: the teaching and management is very difficult to have the opportunity to attend education master degree. Some colleges and universities in order to ensure the training quality, asked master of education must be a full-time at least study 1 year in school, teachers worry a significant number of small and medium-sized school full-time work, is not willing to make the teaching and management enter an examination. So with the national professional master degree of education, the purpose of the training high-level personnel for basic education cause. The teacher who get a master degree for admission course teachers learn less affected returns, and can cause stress to the backbone teachers, affected their work enthusiasm. Master of education enrollment is generally in accordance with the foreign language, the pedagogy, psychology that state exam score to delimit specialized courses in political theory, as a reference point, by the institutions of higher learning themselves proposition. As a comprehensive ability examination into the scholars of the interview, often ignored by the various training unit.

To solve the above problems, the following measures for reference: stop fully off-job learning system, and apply a system of part-time working, summer and winter vacation in class, make key management of personnel and teacher with learning opportunities, conditional region, encourage nearby, implement localization education master degree graduate student training. Implements national exams for specialized courses, the result included in the total score. Or, even for professional class does not implement national exams, proposition examination by the schools themselves, also want to will be included in the total score. Strengthen the interview process, improve the interview result, further improve the professionalism of the exam. Reduce rigid requirements on foreign language achievements, there are three ways to choose from: first, the foreign language result only as a reference point, second, the students of different age discrimination in foreign language performance requirements, third, the cancellation of foreign language test. To do so, be helpful for some rich management experience and the foreign language training practitioners have the opportunity to obtain a higher degree.

Colleges optimal its accommodation what is limited scale frequently departments which do not want full-time study, because the crowding is inherently poor education resources. And read the most complete support degree, otherwise they have no chance to come out to learn this is the last. A small firm support for the full-time, they have to leave the original unit to another job or plan to test abundantly. From then on, it can be seen that different main body as the holding position, represented the interests of the different, have different opinions for the training mode and approach to learning. This paper argues that satisfy the most learners are cultivation unit considering the best interest of the model and study way of the most important criteria. Based on this, this paper argues that not only the working part-time training mode is the most beneficial to expand the scale of cultivation so as to benefit more education workers.

\section{The Writing and Guidance of Essay}

From the point of the author's school, some education master degree graduate student dissertation quality is very high, even more than academic graduate level. But nationally, thesis 
writing and guidance in education master degree graduate still exist many problems:

Paper overall level is not high, academic norms is not enough. Someone is emphasizing the training target of vocational education master major degree and practical at the same time, the opposition to education master degree graduate dissertations academic requirements are putting forward. Academic requirement is a basic requirement, the graduate student should know how to put forward and define the problem, how to access and analysis of literature, how to prepare the questionnaire and interview, how to explain, analyze and solve problems. These are the basic academic training, improve the quality of their thinking and writing level, to improve their found problems in the practical work, the ability is very helpful to solve the problem. Thesis topics and writing to insist on the unification of the theory and practice, the unification of the academic and applied.

Paper with practice is not enough, thesis aimed big and empty, cannot be combined with individual studies in the practical problems in work, this paper writing to improve their practical work, wouldn't help very much. Education master degree graduate students have abundant working experience, have deeper understanding to the real problem, should guide them give full play to its advantages, actively carry out action research.

Some schools, tutors, students' thesis writing not value, think education master degree graduate student's thesis writing role in the whole training process is not as important as academic graduate student thesis writing, it is a small train link, the cultivation of the postgraduate education master major degree is given priority to with course study, should not give priority to with paper. Some even argue that cancel the thesis writing and education master degree graduate students into master course. In addition, some mentors have poor ability, some units even without any education based on practice training base and research paper writing under the guidance of teachers.

Courses and thesis writing without organic link, into two isolated phase. Course learning phase accumulation of knowledge is the base of thesis writing, essay writing should make full use of various curriculum stage learning knowledge.

To solve the above problems, the first to ask a question: why let education master degree graduate student write a paper? The author thinks that writing a paper is for the purpose of training thinking, help education master degree graduate students learn science, rigorous thinking methods, especially the scientific, rigorous method of action research. Once learned the action research, they will be a lifelong benefit. This than to teach them some specific subject knowledge to be more valuable.

To improve the quality of degree thesis, there are a few points need to note: first of all, both in academic and practical at the same time improve the requirements, to strengthen the monitoring and evaluation of paper quality. Secondly, put forward clear request for thesis writing paradigm, to ensure that graduate students learn to action research. Third, learning courses and thesis writing two learning phase relation and interaction, can put forward the paper selected topic moved forward to the early stage of the course, so that we can make graduate student with questions to learn knowledge, enhance pertinence. Fourth, increase the opening review link, jointly by the expert group.

All in all, improve the education management direction education master degree graduate students education quality, is a comprehensive system engineering, from the recruitment of students test to each link between the dissertation further room for improvement. Improvement is the key to use the concept of lifelong education, lifelong learning commander in chief, reengineering and optimization of the whole training process.

\section{Conclusion}

The quality of graduate education in professional degree requirements by mentors and education. Mentor the level and quality of their direct impact on a full-time professional degree graduate training quality, quality of teacher is a key factor in determining the quality of professional degree graduate students. In full-time professional degree education, the construction of the contingent of tutors, one is to emphasize is given priority to with with master, doctor degree of teachers, and 
constantly improve the doctorate in proportion to the teacher. The second is a mentor selection and examination way of dynamic management, superior bad discard, competition, maximum limit arouse the enthusiasm of teachers. Three is to establish a perfect open faculty management mechanism. Four is to strengthen the business training and management of teacher, take the way of going out, please come in and send professional degree postgraduate tutor to enterprise scientific research practice, together with the enterprises to carry out the project research, through the scientific research cooperation to understand the new technology, new standard of the industry, improve the level of teacher's own application technology, enriching the experience in engineering practice.

In the field of professional degree education with professional requirements as the guidance, or there will be no vitality. Specific include: one is the professional degree graduate education units shall take the initiative to meet the needs of economic and social development and labor market, strengthen the cooperation with government related functional management departments, personnel training target should be in conformity with the professional demand. The second is to make the professional degree courses and the professional qualification exam content relative to meet. Three is related to industry and government departments (personnel and labor department) step in the process of professional degree education in time, involved in the curriculum, the evaluation of teaching and credit approval, gradually establish a professional degree postgraduate education to train between vocational qualification certification.

\section{References}

[1] X.N. Zhu, people-oriented Teacher Management Mechanism and Motivational Strategy [J]. Maritime Education Research, (2006) No. 2, p.79-81.

[2] Wu Ying. Discuss on the college work of managing and educating people in the new era [J]. Magnificent Writing, 2013 (24).

[3] Welch V, Security Architec-ture for Open Grid Servces[Z]. OGSA Security Workgroup , 2003,55-63. 